\title{
Comparative study between debris flow of wide-gentle and narrow-steep channel based on numerical simulation and prevention measures
}

\author{
*Han Mei', Hu Xiewen ${ }^{2,3}$ and Hu Kai ${ }^{2}$ \\ ${ }^{1}$ School of Mathematics, Southwest Jiaotong University, China \\ ${ }^{2}$ Faculty of Geosciences and Environment Engineering, Southwest Jiaotong University, China \\ ${ }^{3}$ State and local Engineering Laboratory of Spatial Information Technology of High-Speed Rail Operation. \\ *Corresponding author: han80mei@163.com
}

\begin{abstract}
Along the Duwen freeway in the Wenchuan earthquake area, there are two main types of debris flow channels, that is, wide-gentle channel and narrow-steep channel. The wide-gentle channel has the feature of gentle longitudinal slope, large mean width and catchment area. Whereas the narrow-steep one generally shows opposite features with narrow longitudinal slope, small mean width and catchment area. During the heavy rainfall, these channels are subject to large-scale debris flows due to huge amount of earthquake-induced collapsing and sliding materials. With field investigation on the formation conditions and development characteristics in the Taoguan and the Mozi gullies, we analysed the resulting impact, burying and blockage to the Duwen freeway and the Minjiang River. The sediment characteristic in the above-mentioned types of debris flow gully was intensively studied. Finally, prevention measures of the debris flow and effectiveness analysis of the treatment were proposed based on the features of the two types of channels.
\end{abstract}

Keywords: Wide-gentle channel, Narrow-steep channel, Sediment characteristic, Treatment measures

Paper Received: 29 Jan 2018

Paper Accepted: 12 March 2018

\section{INTRODUCTION}

After the Wenchuan earthquake on May 12th 2008, the large-scale debris flow usually occurred in group accompanied with the river-blocking incidents under heavy rainstorm. In this thesis, we focus on the extra-large group of debris flows occurred on July 10th 2013 along the Duwen freeway in Sichuan province. There were about 17 chief debris flow gullies outburst in this incident, which were distributed on the both sides of the Minjiang River (Fig. 1), in particular the wide-gentle channel and narrowsteep channel formed in the Taoguan gully and the Mozi gully, respectively. At present, people often adopted experimental method, mathematics models, as well as numerical simulation to study the hazardous area of the debris flow. The prediction consequence always revealed the kinematic parameter values in a finite number of spots, lack of description of the dynamic characteristics in the whole process of the debris flow. In this thesis, we will adopt large-scale fluid dynamics software CFX to simulate the dynamics of the two channels under 50-year storm event. Through the investigation of the velocity field distribution and influence on constructions along the debris flow gully, we analysed the validity of the simulation results compared with the actual circumstance. Meanwhile, we will study its impact force and the corresponding risk on the bridge pier of the Duwen freeway and evaluated the destructive effects on the Duwen freeway bridge, blocking of the Minjiang River and the flooding of residents of settlements. Finally prevention measures of the debris flows will be proposed respectively based on the features of the two channels.

\section{The outbreak circumstance of the debris flow on 10th} July 2013

After Wenchuan earthquake on May 12th 2008, a huge amount of loose sediments triggered by the earthquake was distributed in the valley along the Duwen highway. Under the storm circumstance, landslides and debris flows occurred regularly. Especially on July 10th 2013, hundreds of debris flow gullies outbreak at the same time in Wenchuan County, which destroyed the buildings, blocked the river and cut off the express way. In the Wenchuan earthquake region, the debris flow hazard is higher than before and the impact may continue for next 30 years or even longer (Fan and Huang, 2013). As shown in the reference document, the amount of the catastrophic debris flows reached 3.5 times of the landslides (Huang, 2011).

Specifically, the activity characteristics showed that, the type number and quantity of material increased, the initiating mode changed, the hazard scale enlarged, the critical rainfall decreased, and the outbreak frequency improved, as which were shown below.

(1) Many kinds of material with the sharply increasing amount: According to statistics, the collapse and landslide area occupied $7 \%$ of the total area of Minjiang River, with the loose material of $2.13 \times 10^{8} \mathrm{~m}^{3}$ (Liu et al., 2012), as well as the amount of loose material per unit area reached $100 \times 10^{4} \mathrm{~m}^{3} / \mathrm{km}^{2}$ (Cui et al., 2012). As indicated in field investigation, in the debris flow occurred on 10th July, 2013 along the Duwen express way, except for the material in the gully and slope primarily, there 
are some collapsing material triggered by the earthquake act as supplement. At the same time, the activity of the debris flow in earthquake region is tightly correlated with the loose material in the drainage basin. Therefore, the debris flow is easy to outbreak under low rainfall circumstance with the rich loose material.

(2) The debris flow occurred in group, with long time continued: Under the heavy storm on July 10th 2013, only in Wenchuan County there were dozens of debris flow gullies outbreak at the same time, which formed great disasters on the plants, residences and the express way. In the 17 gullies outbreak in July 10th 2013 along the Duwen express way, the duration time reached 1.5 to 3 hours regularly.
(3) The critical rainfall intensity reduced obviously with huge rushing out scale

According to the research in Sichuan Province (Tan and Han,1992), the critical rainfall intensity of the debris flow is 80 to $100 \mathrm{~mm}$, with the one-hour rainfall intensity 30 to $50 \mathrm{~mm}$. For example, in the Longchi Sichuan province before the Wenchuan earthquake, the critical rainfall intensity of the lowfrequency debris flow was very high, which need a"one-in-50 years" to"one-in-100 years" storm. However, on August 13th and 18th 2013, two debris flows outbreak, with the rainfall intensity of "one-in-20 years" to "one-in-10 years" scale. On July 10th 2013, the largest rainfall in 24 hours reached $104 \mathrm{~mm}$, which was lower than"one-in-20 years" rainfall intensity. At

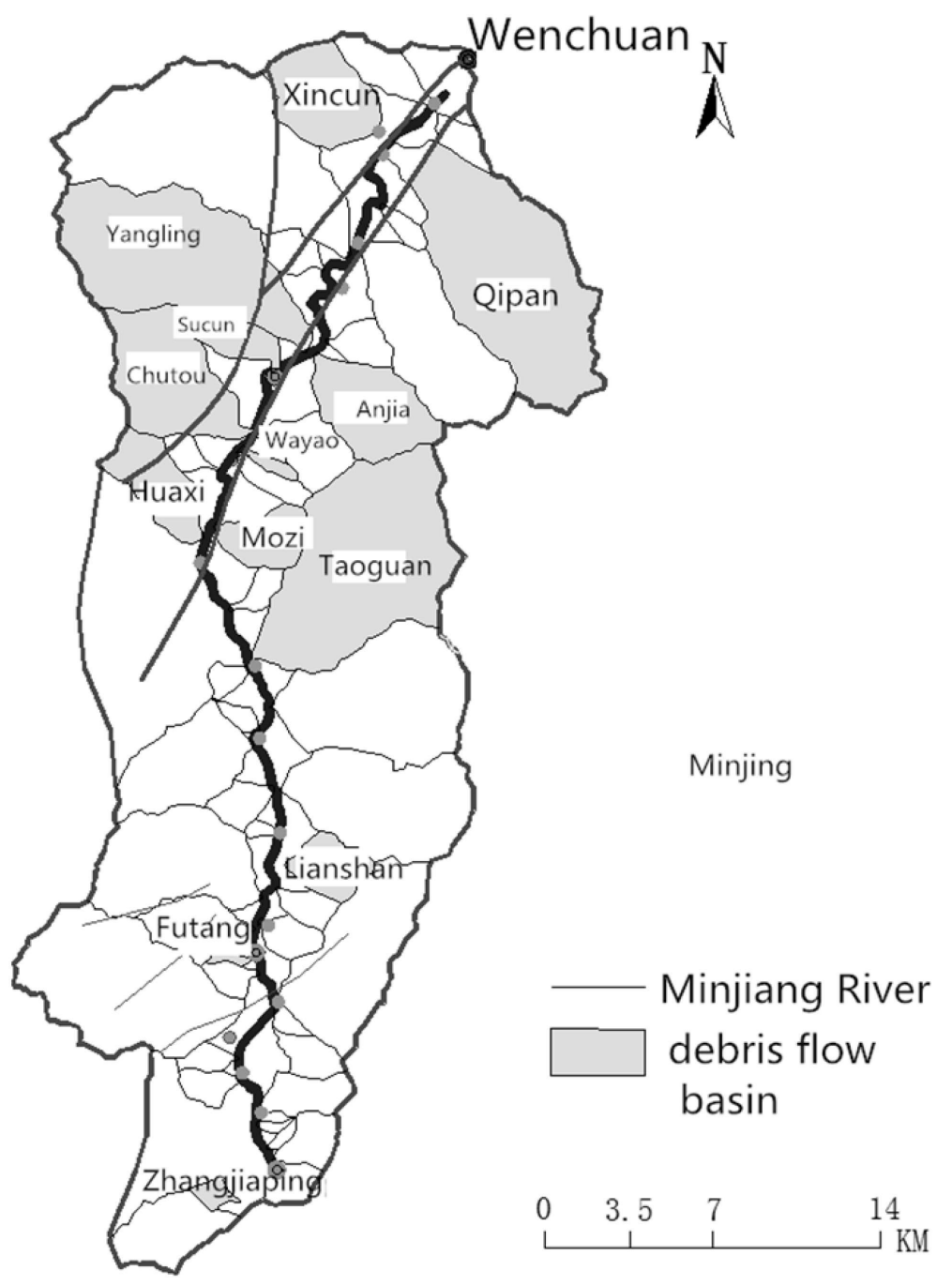

Fig. 1: The distribution diagram of the debris flow gullies along the Duwen freeway 
the same time, according to field investigation and calculation, the peak flow was higher than pre-earthquake. For instance, the rushing out scale of Wayao and the Taoguan gully reached 12 and $108 \times 10^{4} \mathrm{~m}^{3}$ respectively, with the basin area of 1.2 and 51 $\mathrm{km}^{2}$.

(4) Severe secondary disaster, always forming disaster chain: After Wenchuan earthquake, the loose material in many gullies improved largely, which made the debris flow scale reach twice as before. In debris flow disaster occurred on 10th July 2013, the secondary disaster induced by river-blocking was the most prominent, with the specific performance of elevating the main river, squeezing and blocking the river severely. On July 10th 2013, the debris flow occurred with the peak flow of $2353 \mathrm{~m}^{3} / \mathrm{s}$. When the material with big flow rate and amount rushed into the Minjiang River, it spilled over the gully, with $300 \mathrm{~m}$ long, $150 \mathrm{~m}$ wide and 8 to $15 \mathrm{~m}$ thick formed and the river blocked. The upstream of the barrier elevated 8 to $10 \mathrm{~m}$ and caused $5 \mathrm{~km}$ backwater, which drowned the residences and the plants. Then the outburst of flood made the traffic interrupted following the river-blocking. The disaster chain after the debris flow occurred on July 10th 2013 can be concluded as debris flow turns to blocking and burst enlargement, then turns to super-huge debris flow, then turns to barrier lake formed by river blocking, finally turns to flood disaster.

\section{CLASSIFICATION OF DEBRIS FLOW GULLIES IN THE WENCHUAN EARTHQUAKE REGION}

In Wenchuan earthquake region, two types of debris flow gullies are in common. These are wide-gentle and narrowsteep debris flow gullies. Generally, people always pay more attention on the wide-gentle debris flow gullies due to plenty of engineering activities, residences and hydroelectricity facilities in this kind of debris flow gully. While in narrow-steep debris flow gully, the circumstance is on the contrary, the steep slope is unsuitable for construction. However, due to the steep slope and smaller basin area, the material in this kind of gully can form emergency debris flow and cause destructive impact. These two types of debris flow gully are different in terrain, basin shape and gully slope, which resulted in the diversity of the catchment, material initiation and the sediment characteristic. Whereas the risk degree of the debris flow gullies belonging to both types was the same high with different governance measurements (Han et al., 2015).

\section{Wide-gentle debris flow gullies}

Wide-gentle debris flow indicates that the debris flow gully of this kind possesses large drainage basin area, wide neighbor ridge, small longitudinal gradient and well developed branches. The specific representations are as follows: 1) drainage basin area larger than $10 \mathrm{sq} . \mathrm{km} ; 2$ ) average longitudinal gradient less than $200 \%$; 3) partial width can reach 80 to $100 \mathrm{~m}$.
Among the 13 debris flow gullies outbroke along the Duwen express way on July 10th 2013, the Taoguan gully has the channel length of $4 \mathrm{~km}$ and gully width of 60 to $130 \mathrm{~m}$ (Fig. 2), The Qipan gully has the average gully width of 50 to 120 $\mathrm{m}$, the Chutou gully has the average gully width of 50 to 120 $\mathrm{m}$. According to the definition, these three gullies mentioned above all belong to the wide-gentle type.

Wide-gentle debris flow gully always takes shape of "U", with broad gully bottom, large basin area and open channel and high cut density, to develop collapse and large-scale landslide. At the same time, this kind of debris flow gully tends to form barrier lakes because of the widespread main channel and branches. In the following two rainy seasons after the Wenchuan earthquake, many debris flow gullies outbroke in main channel and branches under low rainfall intensity. However, due to the finite scale, the factories at the exit of the Taoguan gully material deposited in branches and barrier lakes instead of rushing out of the exit. While under the severe storms, the combined effect of the ancient sediment and multistage barrier outburst always lead to the large rushing-out-scale debris flow.

Simultaneously, the wide-gentle debris flow gully showed scour and deposition characteristic at the same time. Therefore, most of the rushing-out material from the branches deposited in the main channel, with less material entered into the Minjiang River. Meanwhile, a large amount of debris flow material deposited in the currency area will form a new circle of debris flow under the late water flow effect through gullying and sideerosion supplement. Obviously, the plugging and bursting of the barrier lake is the key problem in the eruption of the widegentle gully. While selecting the treatment measures, the most important thing to be note should be to eliminate the harmful impact produced by the plugging and bursting.

\section{Narrow-steep debris flow gullies}

Combined with field investigation of the basin shape, we defined the narrow-steep debris flow gully with narrow

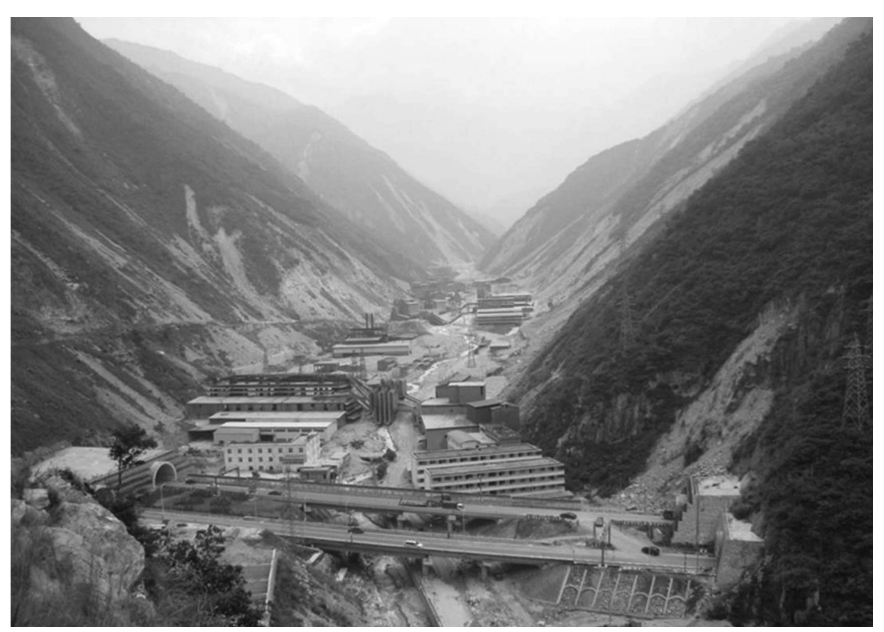

Fig. 2: Distribution of residential area 
neighbor ridge, steep longitudinal gradient and rich sediment provenance. According to this definition, the main representation of narrow-steep debris flow gully is: 1) drainage basin area less than 2 sq. km;2) average longitudinal gradient bigger than $300 \%$; and 3 ) the average basin width less than 50 . The typical narrow-steep gully is such as the Mozi gully, the Wayao gully, the Futang gully and so on. These gullies have the basin width of 5 to $30 \mathrm{~m}$, take the shape of "V" with well-developed steep ridge, water fall and the sudden-rising-fall characteristics.

Take the Mozi gully for example, there are many kinds of harmful ecological phenomenon such as collapse, landslide and unsteady slope, which contributed to the collection of the loose solid material (Fig. 3). Because of the little basin area, as well as the small average width, the material is likely to concentrate and activate under the effect of rainfall and steep terrain. The lasting time always short and once there are some barrier body in the basin, it will result in the remarkable enlargement of the rushing out scale of debris flow.

In aspect of forming mechanism, the narrow-steep debris flow always center on the retrospective erosion and revelation. The scour and deposition characteristic shows the resource shaving throughout the journey with no chance for deposition. Affected by the steep terrain, the loose solid in the channel is hard to stay, so the barrier lake is uneasy to form. Therefore, the key problem of the treatment is preventing the retrospect erosion and channel undercutting.

\section{COMPARISON OF THE TWO TYPES OF DEBRIS FLOW GULLY THROUGH NUMERICAL ESTIMATION}

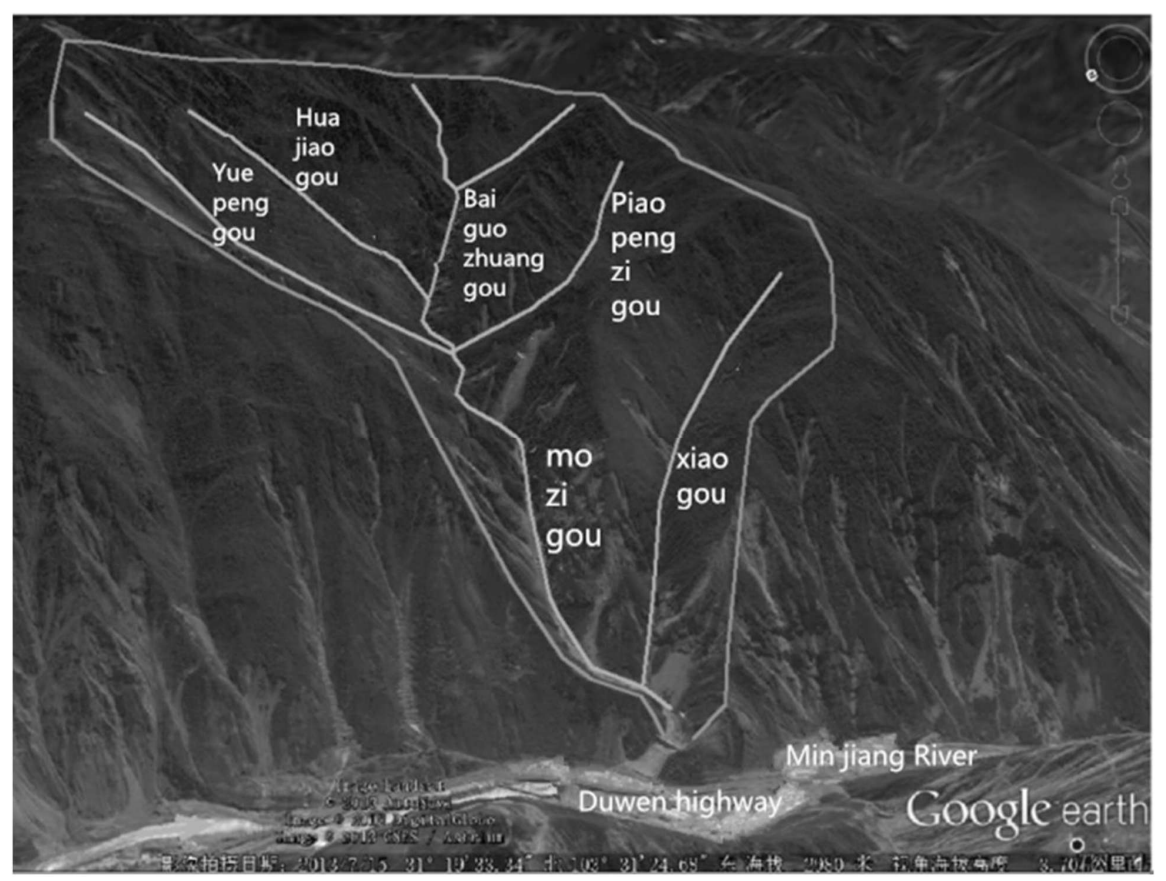

Fig. 3: Sketch map of the drainage basin in the Mozi gully
Despite of significant difference in morphology, hazard mechanism, deposition characteristic and secondary hazard chain of these two types of debris flow gully, the risk degree is similar (Han et al., 2015). Therefore, we studied both of them and put forward the disposal engineering measurement respectively, which will be very important in both theoretical and practical significance.

\section{Wide-gentle debris flow gully}

On July 10th 2013, a large scale of debris flow occurred in Taoguan gully, with many residential areas, factory plants and the Duwen highway destroyed or buried by a large amount of sediments, which caused a direct economic loss of 200 million of RMB. As recorded in history, Taoguan gully is an ancient typical debris flow gully. On May 12th, 1890, the debris flow occurred and hurt thousands of people in this accident. After this accident, there were three times of debris flow, which occurred in 1960, 1982 and 1992. The Taoguan debris flow occurred with the feature of Long time duration, giant rushing out scale, advanced in staggered peak, and period flow. Take the Taoguan gully for example, we studied the sediment characteristic of wide-gentle debris flow gully through numerical estimation.

Performed numerical simulation based on CFX of the Taoguan gully debris flow, we took the transportation area of the Taoguan gully crossing the Duwen highway as the range of numerical simulation. Then built the model and divided it into grids, with the plane range of 500 meters length and 300 meters width.

Next we set the boundary conditions, as well as designed 


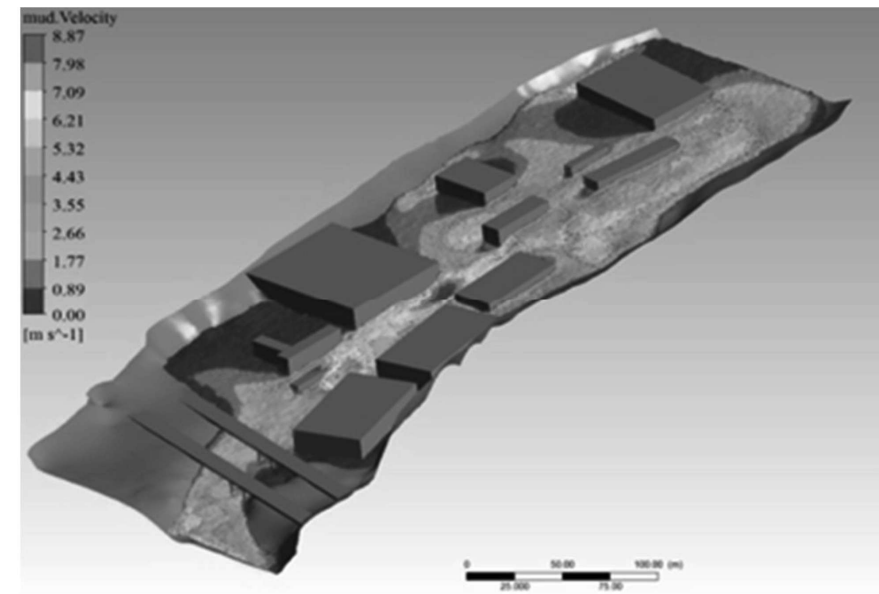

Fig. 4: Velocity map of the Taoguan gully

the quantity of flow. Limited by the simulation software and combined the outburst time, we set the numerical simulation time as 1800 seconds, with time step of 1 second. The two peak moments arrived at the 6th and the 23rd second respectively. Then we monitor the quantity of flow at the entrance and exit of the debris flow. By using the Bingham body rheological model, we got the simulation animation of the debris flow occurred in the Taoguan gully. As was shown in this simulation result, the debris flow formed under "one-in-50 years" storm will spread and bury part of low residences, some factories and nearby highway. Taking the overflow range at the moment of 530th second as the risk range, as shown in Fig. 4, we found that the consistency of the simulation range and the actual rage is nearly 90\% (Han et al., 2016).

\section{Narrow-steep debris flow gully}

Numerical simulation based on CFX of the Mozi gully debris flow was conducted. The exits of the Mozi gully and the buildings were taken as the range of numerical simulation, with the plane range of $500 \mathrm{~m}$ length and $350 \mathrm{~m}$ width. The assumption and boundary conditions, as well as the grids division were set to the simulation of the Taoguan gully. The numerical simulation time was set as 1800 seconds, with time step of 1 second, by

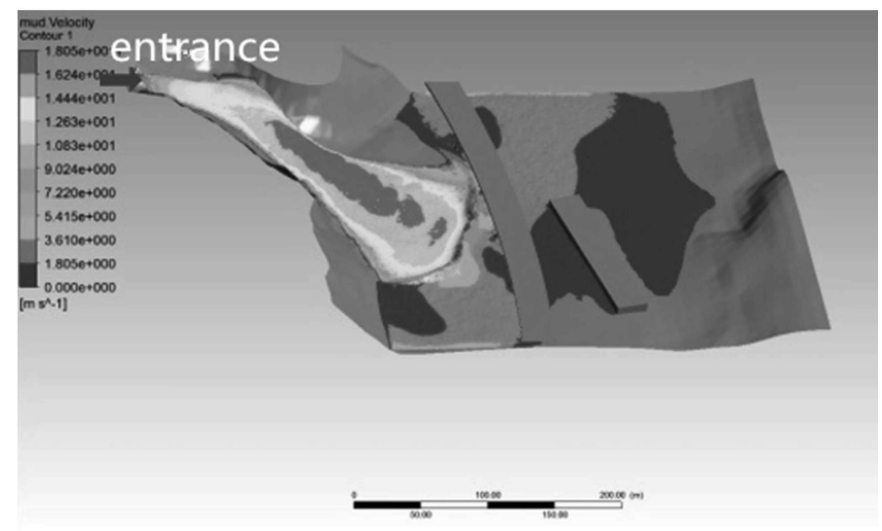

Fig. 5: Velocity map of the Mozi gully using the Bingham body rheological model, we got the simulation animation of the debris flow occurred in the Mozi gully as shown in Fig. 2. The overflow range at the moment of 700th second as the risk range was taken and found that the consistency of the simulation range and the actual rage was nearly $87 \%$ (Fig. 5).

\section{CONTRAST OF THE TREATMENT MEASURES}

Abundant loose solid material and plentiful of water energy act as the key factors of debris flow formation, Therefore, the treatment measures can be selected as silt arrester, bedsteady project, drainage engineering, stop and deposit field. These four meastures were often used in combination to reduce the disaster effects, viewing pecularities of debris flow occurred on July 10th 2013. From the comprehensive consideration of formation condition, channel characteristic and prevention target, we took many kinds of measurement combined as regard to different type of debris flows to get the due effect of hazard prevention.

The wide-gentle debris flow gully has the relatively larger basin area and many branches and abundant material. Although the hazard frequency is fairly low, the scale and hazard will be huge once the debris flow occurs. The gully is broad in the middle and downstream areas with capacity to obstruct large scale material. While carrying out the treatment measures, instead of draining the material directly into the main river, it is suitable to adopt the administration idea of taking the intercepting as priority, while the drainage as minority. Through building multilevel dam, especially the medium to high dam (with effective height of $10 \mathrm{~m}$ above), rushing out material from the branches and the large collapse can be maintained. Meanwhile, the drainage water channel is constructed in the downstream section to drain the flood under or over the design

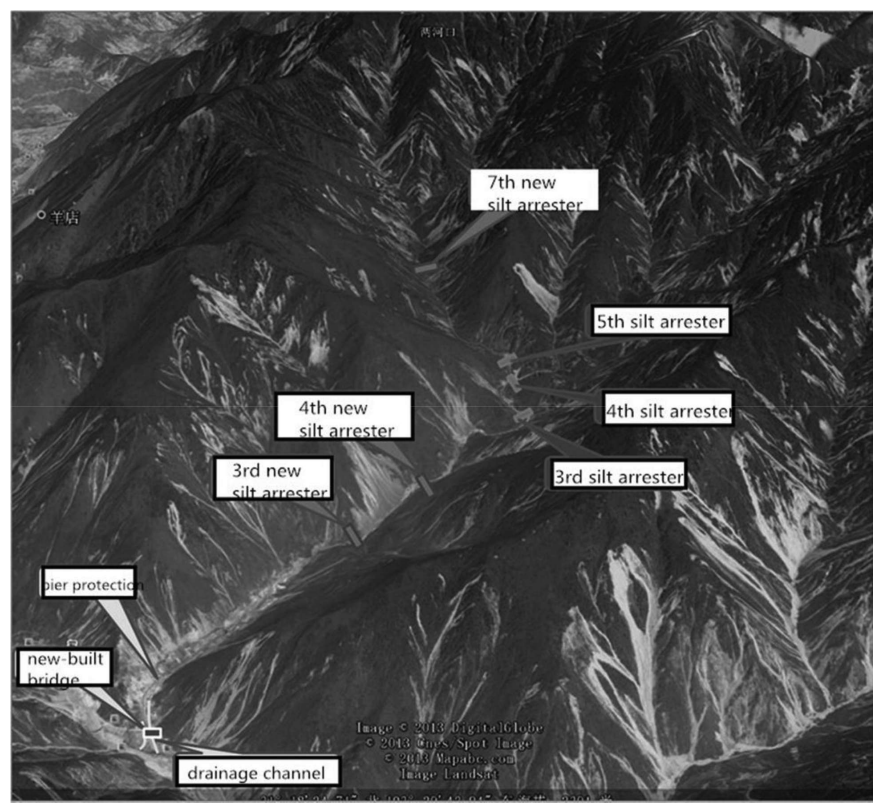

Fig. 6: Engineering distribution in the Taoguan gully 
standard thus the channel can achieve the purpose of comprehensive treatment. For example, in the administration of the Taoguan debris flow gully, the multilevel obstructing system was constructed, including three new-built dams and 3 ancient dams reinforced. The drainage channel elevated in the downstream section has developed good hazard prevention effect (Fig. 6).

Although the narrow-steep debris flow gully has relatively small basin area, a series of hazard chain will form due to a large-scale material rushing-out quickly and give rise to the blocking at the exit of the river easily. In respect to prevention measures, the suitable managing theory should be adopted is to fix the slope and maintain the material in the channel, as well as handle the blocking and sediment at the exit. Firstly, we should fix the bed and stabilize the slope in the section where channel material is abundant in order to prevent the motivation of large scale resource. Secondly, we can adopt the assistant dam to stop the debris flow if the terrain condition is suitable at the entrance. For example, a $25 \mathrm{~m}$ high dam and stopping yard was built at the entrance of the Mozi gully with fine implementation effect (Fig. 7).

\section{CONCLUSIONS}

Based on field investigation, the debris flow outbreak on July 10th, 2013 had shown many new characteristics, such as sharply improved material, long persistent time, obviously decreased critical rainfall, huge rushing out material scale and hazard chain outbreak regularly. Combined with the terrain feature, development characteristic and hazard mechanism, the debris flow gullies are divided into two types, which are widegentle and narrow-steep. Through the comparative research of the erosion and deposition characteristics and its treatment measures, the conclusions are as follows:

(1) The wide-gentle debris flow always performed more prominent blocking and crumbling effect, which is scouring as well as burying, and the burying is of priority. Therefore, the choosing of treatment measure is eliminating the harmful influence of the blocking spot.

(2) The narrow-steep debris flow gully performed shoveling along the way, with no chance for stopping and burying. The formative and circulated area is distributed in the whole gully, the loose material is hard to stay, so the barrier lake is hard to take shape. Therefore, the key point of the treatment measure is preventing the tracking erosion and gully undercutting.

(3) By using the CFX software to simulate the dynamic process of the Taoguan and the Mozi debris flow gullies, we came to the conclusion that, the risk scope, the whole pushing velocity and the river-blocking degree of the debris flow all coincide with the simulation result, which verify the reliability of the numerical simulation.

(4) As regard to the choosing of the treatment measures,

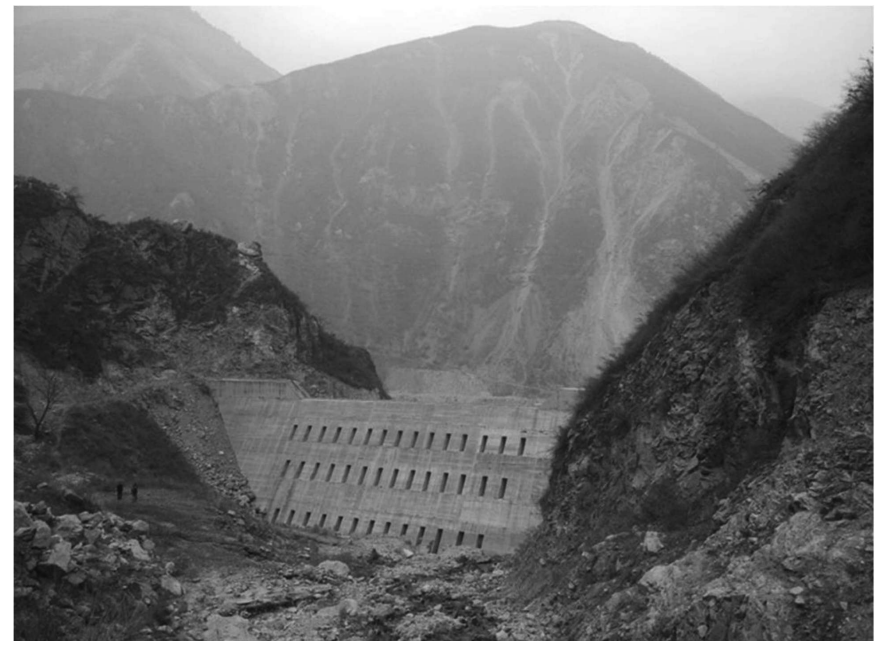

Fig. 7: The new-built silt arrester at the exit of the Mozi gully

it is suitable to adopt the idea of take priority of intercepting as well as drainage assisted. However, due to the rushing velocity and loose material quantity, it is easy to block the gully of narrow-steep debris flow, thus cause more severe hazard. The suitable treatment measures are to make material and flow steady while retarding and depositing the material at the exit.

\section{REFERENCES}

Cui, P., Zhuang, J.Q., and Chen, X.C., 2010, Characteristics and Countermeasures of Debris Flow in Wenchuan Area after the Earthquake.Journal of Sichuan University ( Engineering Science Edition), v. 5, pp. 10-19.

Fan, X.M. and Huang, R.Q., 2013, The Landslide Story. Nature Geoscience, v. 6, pp. 325-326.

Han, M., Hu, X.W., and Diao, R.H., Numerical Simulation of Dynamics Character of Taoguan Debris Flow Gully at Duwen Highway Segment in Wenchuan Earthquake Disaster Region, 2016, Journal of Sichuan University(Engineering Science Edition), v. 1, pp. 35-42.

Han, M., Hu, X.W., and Liang, J.X., 2015, Risk Evaluation of Debris Flow along Duwen Highway Using Optimal Combination of Empowerment. Mountain Research, v. 5, pp. 597-602.

Huang, R.Q., 2011, Effect Analysis of the Ecological Hazards after Wenchuan Earthquake. Journal of Engineering Geology, vol. 2, pp. 145-151.

Liu, J.F., You, Y., and Chen, X.C., 2012, Potential Damages and Identification of Debris Flow Barrier Lakes in the Upper Min River Drainage. Journal of Geoscience, v.7, pp. 885-891.

Tan, W. P. and Han, Q. Y., 1992, Regional Critical Rainfall Indicator Research of Debris Flow Forecasting in Sichuan Province. Journal of Catastrophology, v. 2, pp. 37-42. 